\title{
RECENSIONES Y NOTAS BIBLIOGRÁFICAS
}

Eleuterio R. RuIz, La tierra es para los pobres. El Salmo 37 y su mensaje siempre actual (Profundizar la Palabra), Buenos Aires, Asociación Bíblica Argentina - PPC, 2016, 106 pp., ISBN: 978-987-740-155-4.

La obra está basada en la tesis doctoral que el autor defendió en el Instituto Bíblico de Roma y que fue publicada en 2009, pero resume el trabajo exegético en que se fundamenta y ahorra citas en lengua original. Lo primero porque no sería de interés para el lector común que busca conocer más de los textos bíblicos y lo segundo porque el público al que está dirigida la colección en que se publica (Profundizar la palabra) normalmente desconoce las lenguas antiguas.

Dicho esto, es de celebrar que el contenido de tesis doctorales se publiquen en formato accesible al gran público, no solo porque permite ampliar los lectores sino también porque el género literario "tesis doctoral" sumerge en una inevitable maraña de tecnicismos las perlas que en definitiva iluminarán el sentido de un libro, un pasaje, un salmo. Pero sabemos que para el autor es un esfuerzo considerable producir un trabajo de esta naturaleza, pues todo lo dicho en la obra de origen tiene sentido y es difícil elegir qué se trasladará y qué no a la nueva obra.

Esta obra tiene seis capítulos. Luego de una breve introducción se abre con el que es el más extenso, y nos atrevemos a decir que es el que más apreciará el lector no especialista. En él se ubica al salmo 37 en el contexto del siglo III a. C., en la época tolomea, y se menciona la existencia de escribas que a la vez que tenían el oficio administrativo, también utilizaban sus conocimientos de la escritura para producir obras como el salmo que ocupa este libro. En una perspectiva que es cara a la lectura latinoamericana, Ruiz señala que los campesinos tenían "la fe y la vida", pero necesitaban de quien pusiera por escrito sus sufrimientos y su visión de la relación de Dios y el pueblo pobre. En una primera aproximación al mensaje del salmo, se dice en p. 11 "El Salmo 37 quiere dar una respuesta, una palabra que ilumine la vida de estos campesinos pobres desde la fe y que los ayude a encontrar una esperanza". A continuación se ofrece una traducción propia del salmo, que busca ser "de estudio" y que trata de reflejar las inflexiones del texto hebreo, aun a costa de perder elegancia. El autor aprovecha la traducción para presentar la estructura del salmo y le agrega títulos que facilitan la lectura y comprensión de su 
mensaje. Luego dedica 38 páginas a comentar el salmo, sus detalles, temas, teología, lo que hace siguiendo el esquema de tres partes en que lo dividió.

Los capítulos 2 a 4 están dedicados al lugar en el canon del AT, el siguiente a la recepción del salmo en la comunidad de Qumrán, y el 4 a comentar su mención en Mateo 5,5 en el marco de las bienaventuranzas. En el 2 se comenta su ubicación en el salterio, su relación con otros salmos con los que comparte temas y perspectivas y culmina evaluando su traducción en la Septuaginta. En el capítulo 3 se explica que en Qumrán se produjo un género llamado pesher y que en los manuscritos rescatados encontramos un pesher del salmo 37 completo. El autor lo transcribe y comenta, lo que aporta a la obra algo que no es habitual tener en materiales de este tipo, en particular por la claridad con que expone el tema. Sobre Mt 5,5 se explaya en comentar la importancia de esta mención del salmo en el v. 5 como la tercera de las bienaventuranzas y expone su estructura y cómo la posesión de la tierra, que es propia del evangelio de Mateo, en este caso adquiere un valor escatológico. En Mateo el uso del salmo 37 conduce a que poseer la tierra no sea solo una referencia a la tierra material sino que adquiere una dimensión trascendente. El libro cierra con los capítulos 5 y 6 dando una recorrida a la interpretación del Salmo 37 en autores antiguos y actuales.

Este trabajo de Ruiz tiene muchos valores. En principio ya mencionamos que expone en el primer capítulo su contenido y lo comenta en un lenguaje sencillo. El resto de los capítulos sirven para que el lector no especialista tengo una visión de las distintas dimensiones que tiene el estudiar un texto bíblico, en este caso un salmo. Pasar por la literatura de Qumrán, por la LXX, por la recepción en el NT, y por las lecturas que van desde la sinagoga y los padres de la iglesia hasta Walter Brueggemann y Norbert Lohfink enriquece el conocimiento de la Biblia y de lo que es leerla en profundidad.

El libro contiene numerosos cuadros a modo de excursus que explican aspectos de la disciplina bíblica: el salterio; géneros literarios; poética hebrea; los salmos en los LXX; y otros. Lleva un prólogo de Norbert Lohfink donde el célebre profesor ubica este trabajo dentro de una nueva generación de biblistas latinoamericanos. Quien lea esta obra, que recomendamos con fruición, verá que está en lo cierto.

Pablo R. Andiñach Pontificia Universidad Católica Argentina andinachp@gmail.com 